\title{
The use of documentary sources for reconstructing flood chronologies on the Amalfi rocky coast (southern Italy)
}

\author{
S. Porfido ${ }^{1, *}$, E. Esposito ${ }^{1}$, F. Alaia ${ }^{2}$, F. Molisso ${ }^{1} \&$ M. Sacchi ${ }^{1}$ \\ ${ }^{1}$ Institute for Coastal Marine Environment (IAMC) - CNR, Calata Porta di Massa 80133 Naples, \\ Italy \\ ${ }^{2}$ Campobasso State Archive, Via degli Orefici 43, 86100 Campobasso, Italy \\ *Corresponding author (e-mail: sabina.porfido@iamc.cnr.it)
}

Documentary source materials are essential for retrospective reconstruction of flood events occurring in past centuries. This paper presents methods of research and archiving of historical data from the 16th century to the present. The quality and completeness of the various original sources were evaluated and carefully analysed in their historical context, to avoid serious mistakes. Systematic investigation of about 3000 documents, mainly found in national State Archives and libraries, allows us to identify and localize at least 106 flood events occurring along the Amalfi coast (southern Italy) for five centuries between the years 1500 and 2000. The collected data provide useful details on flood dynamics, size of flooded areas, flood duration, damage level, number of victims and induced geological effects. When available in sufficient quantity, the flood data allow determination of very useful parameters such as the severity class, to identify large floods and their recurrence interval. 